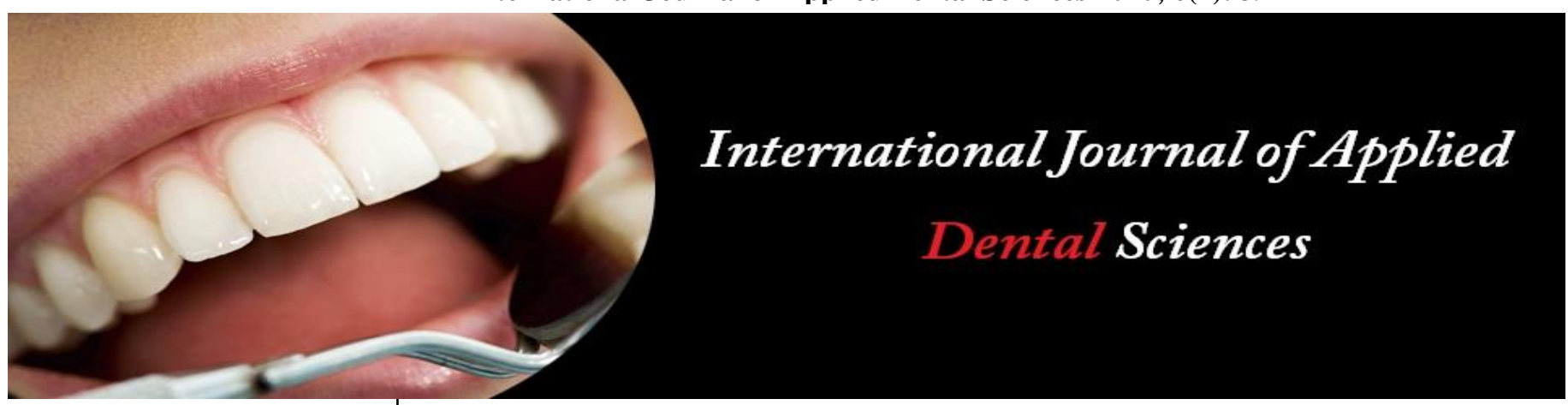

ISSN Print: 2394-7489

ISSN Online: 2394-7497

IJADS 2020; 6(4): 39-41

(C) 2020 IJADS

www.oraljournal.com

Received: 10-08-2020

Accepted: 28-08-2020

Ajay Balasaheb Mohite

Oral \& Maxillofacial Surgeon-

OraMax Oral Surgery Clinic, $1^{\text {st }}$

floor, surya commercial complex,

Opp. St Paul School, Civil

hospital road, Satara,

Maharashtra, India.

Sudhir Ramlal Pawar

Oral and Maxillofacial Surgery-

Assistant Professor, Bharati

Vidyapeeth Dental College and

Hospital, Pune, Maharashtra,

India.

Siddharth Shrikant Joshi

Periodontist and Implantologist-

Joshi's Dental Clinic and

Implant centre, shop no.6,

Sanjay pride, Devi chowk,

Satara, Maharashtra, India.

Amit Mahadev Raskar

Oral \& Maxillofacial Surgeon-

Dentocure Advanced dental

clinic, Shop no.3, Krishiratna

apt, Parijat housing society,

Vasant baug bus stop,

Bibwewadi, Maharashtra, India.

Corresponding Author:

Ajay Balasaheb Mohite

Oral \& Maxillofacial Surgeon-

OraMax Oral Surgery Clinic, $1^{\text {st }}$

floor, surya commercial complex,

Opp. St Paul School, Civil

hospital road, Satara,

Maharashtra, India.

\section{MYTHS and reality regarding wisdom tooth in Indian population}

\section{Ajay Balasaheb Mohite, Sudhir Ramlal Pawar, Siddharth Shrikant Joshi and Amit Mahadev Raskar}

DOI: $\underline{\text { https://doi.org/10.22271/oral.2020.v6.i4a.1046 }}$

\section{Abstract}

Around $70 \%$ of Indian population complains of pain due to wisdom tooth, but still try to avoid visits to the dental services just because of fear and various myths about wisdom tooth. In India, people still are unaware about dental treatment facilities and advances reached in the field of dentistry. This may be because of negligence towards proper oral hygiene and dental care. But as the dental fraternity is spreading across the nation, it becomes important to remove the myths and explain the reality about dental treatment and advantages. In this article, we have tried to explain various myths and reality about wisdom tooth in general population.

Keywords: Myths, reality, wisdom tooth, dental hygiene, general public.

\section{Introduction}

Oral Health is one of the most neglected issue in relation to health facilities in India. The oral health standard completely depends upon the socio-economic status, cultural belief, diet, education qualification and health care services in the society. Indian population comprises people of different socio-economic status and cultural background, and mainly due to lack of knowledge and awareness of oral health people believe on various myths and false information. Scientifically, myths are regarded as extensive and unquestioned false perspective that emerges from false traditional beliefs and non-scientific knowledge. As the dental services are spreading country wise, it becomes important to reveal various myths and realities of dental knowledge. Specifically about wisdom tooth, which comprises $15 \%$ of all dental complains is very much neglected and misknowledge field. So, in the article all the various myths and realities about wisdom tooth has been revealed so that people can move on towards newer treatments available across the nation.

\section{Methodology}

Queries was collected from three oral surgery and dental clinic in which patients spoke about their views regarding wisdom tooth. The data collected from 183 patients who had complain about wisdom tooth was divided into two main groups 1) Males (98 patients) and 2) Females (85 patients) which was subdivided into A) Educated (above $12^{\text {th }}$ std) and B) Less-educated (below $12^{\text {th }}$ std) [Table 1]. The chart was made about the queries patients had related with wisdom tooth [Table 2].

Table 1: Number of participants in the study

\begin{tabular}{|c|c|c|c|}
\hline \multicolumn{4}{|c|}{ Number of participants in the study } \\
\hline \multicolumn{3}{|c|}{ Males (98 Patients) } & \multicolumn{2}{c|}{ Females (85 Patients) } \\
\hline Educated & Less-Educated & Educated & Less-Educated \\
\hline 72 & 26 & 64 & 35 \\
\hline
\end{tabular}


Table 2: Patients views regarding wisdom teeth

\begin{tabular}{|c|c|c|c|c|}
\hline \multicolumn{9}{|c|}{ Patients views regarding wisdom teeth } & Agreed & Disagreed & No Knowledge \\
\hline & & $68 \%$ & $9 \%$ & $23 \%$ \\
\hline I. & Eye sight is lost after wisdom tooth removal. & $57 \%$ & $36 \%$ & $7 \%$ \\
\hline II. & Never get your wisdom teeth extracted. & $32 \%$ & $18 \%$ & $50 \%$ \\
\hline III. & Sneezing problem starts once wisdom tooth removal is done. & $63 \%$ & $29 \%$ \\
\hline IV. & Medicines can cure all the wisdom tooth problems completely. & $63 \%$ & $2 \%$ \\
\hline V. & Facial deformity occurs once wisdom tooth surgery is done. & $31 \%$ & $67 \%$ & $20 \%$ \\
\hline VI. & Cancer occurs once wisdom tooth removal is done. & $53 \%$ & $28 \%$ & $5 \%$ \\
\hline VII. & Chewing ability of tooth is lost after wisdom tooth surgery. & $12 \%$ & $83 \%$ & $30 \%$ \\
\hline VIII. & Loosening of teeth starts once wisdom tooth removal is done. & $58 \%$ & $12 \%$ & $15 \%$ \\
\hline IX. & Suturing is more painful than teeth extraction procedure. & $82 \%$ & $3 \%$ & \\
\hline
\end{tabular}

\section{Result}

The total number of participants in our study were 96 males and 85 females. Out of which 72 males were educated while 26 males were less educated and 64 females were educated and 35 females were less educated.

\section{Discussion}

Oral diseases treatment are the fourth expensive treatment for human body [2]. In many low-income countries of the developing world, the total cost of dental procedure would exceed the entire health-care budget ${ }^{[3]}$.

Wisdom teeth, which is also known as third molars, are the last permanent teeth to develop. They most often erupt during a person's late teens or twenties ${ }^{[4]}$.

There are various fevers among the patients related to dental extraction out of which some of them are myths and to know how this myths spread among the people we underwent detail study of each complain.

\section{Eye sight is lost after wisdom tooth removal.}

It is the most common belief among the people that removal of wisdom tooth might lead to eye sight loss. Nearly $68 \%$ people believed in our study. The reason for this misconception may be complex and reflect a combination of limited knowledge regarding the link between oral health and well-being of the body ${ }^{[5]}$.

It is generally agreed that the local anaesthetic solution reaches the orbit through vascular, neurological or lymphatic network [6]. According to various proposed theories, mechanism of occlusion of the artery begins if one administers local anaesthetic solution into arterial vessel which reaches the eye following the maxillary artery/inferior alveolar artery, middle meningeal artery and ophthalmic artery route [Figure no.1]. Amaurosis (partial or total blindness without visible change in the eye), impaired vision and loss of the pupillary light reflex are the clinical features of this particular situation. Once the anaesthetic agent reaches the retinal artery, reflective vasospasm of the central retinal artery induced by either the active ingredient like adrenaline that could result in ischemia and necrosis of the retinal tissue. Paralysis of the sixth nerve following nerve block, as given in dental surgery, was first reported in English literature by Goodside and Weigneist in 1946 for a sphenopalatine block 8 . With this sphenopalatine block entire half maxilla is anaesthetized. However such blocks are very rarely administered in dental offices.

Since then many cases of temporary blindness has been reported and there has been no single case of permanent blindness reported.

However to avoid such complications it is advised to every dental surgeon to administered local anesthesitic agent after negative aspiration of syringe.
Prompt diagnosis and reassurance should be done about occurrence of blindness after administration of local anaesthetic agent to calm the patient. In cases where visual acuity is affected, patients should be advised against dangerous tasks like driving or using sharp instruments, at least until the local anaesthetic effect has worn off ${ }^{[7]}$.

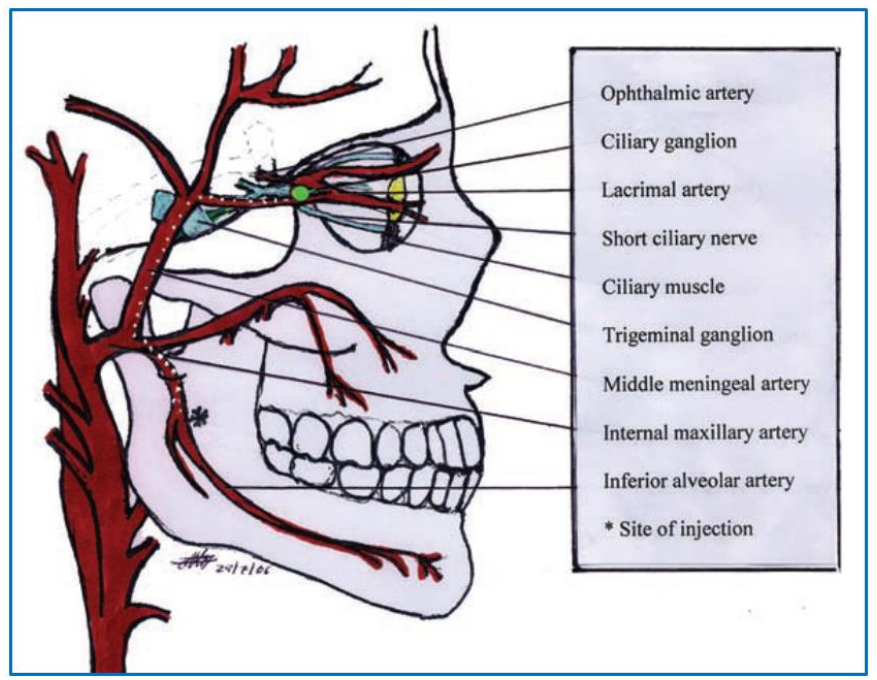

Fig 1: Showing the reverse track of local anaesthetic agent

\section{Never get your wisdom teeth extracted.}

Nearly $57 \%$ of people said that wisdom tooth should not be extracted at any condition. This might be because of inadequate knowledge dental treatment modalities. Also many people have fear of surgical procedures. But one needs do undergo surgical removal of wisdom tooth in situations like grossly carious wisdom tooth, impacted teeth which is causing pain and has inadequate space for eruption.

\section{Sneezing problem starts once wisdom tooth removal is done. \\ Nearly $32 \%$ of people believed that sneezing problem starts once wisdom tooth removal is done. There is no relevant that proof that sneezing problem starts once wisdom tooth removal is done. For procedures of lower wisdom tooth extraction, there is not link about sneezing after the procedures. For procedures of upper wisdom tooth extraction, the roots of upper wisdom tooth are far about from maxillary sinus lining so chances of damage to maxillary sinus is not present and hence it can be said that the is no connect between sneezing problem with wisdom tooth removal.}

\section{Medicines can cure all the wisdom tooth problems completely.}

Nearly $63 \%$ of patients believed that medicines can cure all the wisdom tooth problems completely. It is a misconception 
that medicines can cure all wisdom tooth problems completely. It is believed so because when a patient visits dental office for the first time for pain of wisdom tooth, normally a dentist prescribes antibiotics and analgesic which temporary subsides that pain for few days which makes the patient believe that medicines can cure wisdom tooth problem completely. Infact due to antibiotic and analgesic use patients tend to ignore dental treatment for wisdom tooth which further can make the situation more critical causing swelling, trismus and making tooth extraction procedure more difficult. So it is not true that wisdom tooth problems can always be cured by medicines and negligence for dental treatment can worsen the situation further.

\section{Facial deformity occurs once wisdom tooth removal surgery is done.}

Nearly $31 \%$ of patients believed that facial deformity occurs once wisdom tooth removal surgery is carried out. This misconception is because of inadequate knowledge about dental procedures which lead to create fearful beliefs. There is no scientific proof or any cases reported regarding situations stating facial deformity post-surgical removal of wisdom tooth.

\section{Cancer occurs once wisdom tooth removal is done.}

Nearly $53 \%$ of patients believe that cancer occurs once wisdom tooth removal is done. This misconception is mainly because of lack of knowledge and fear regarding occurs of cancer. Many patients believe that cancer occurs after tooth extraction is done and due to such belief they avoid dental treatment at appropriate time which leads to occurs of severe pain, swelling, weakness, trismus (restricted mouth opening) and can also lead to cystic condition.

\section{Chewing ability of tooth is lost after wisdom tooth surgery.}

$12 \%$ of patients believe that chewing ability of tooth is lost after wisdom tooth surgery is done. It is also a misconception due to lack of knowledge and fear. It is true that removal of teeth can lead to loss to chewing ability but regarding wisdom tooth, it is a vestigial tooth and does not function in mastication (chewing of food).

\section{Loosening of teeth starts once wisdom tooth removal is done.}

$58 \%$ of patients believe that loosening of tooth starts once wisdom tooth surgery is done. It can remain true with any other tooth but with wisdom tooth it cannot be related as true as the wisdom tooth is the most last tooth in the oral cavity. On distal side of wisdom tooth lies mandibular bone, so wisdom tooth only mesial surface is in contact with its adjoining tooth. And once wisdom tooth is removed, after few days bone formation occurs at wisdom tooth place which gives distal support to the adjoining tooth.

Suturing is more painful than teeth extraction procedure. $82 \%$ of people believe that suturing is more painful than teeth extraction procedure. This belief is mainly because many patients have fear regarding suturing. Mainly females were more than males who had fear of suturing. Many female patient believe pain regarding suturing, it is because they have pain during childbirth labour pain which also requires suturing during caesarean delivery.

\section{Conclusion}

From the results of this article, we came to the conclusion that many of the people suffer from fear as well as lack of knowledge regarding dental treatment and especially about wisdom tooth. People should be still made aware about urgency of wisdom tooth treatment so that they do not land up with serious complications. As a dental surgeon, various explanatory camps should be carried to make the people aware of different dental procedures and its advantages.

\section{Reference}

1. Sudarssan SG. Prevalence of Myths and Misconceptions about Dental Extractions among Outpatients of a Private Dental College Hospital. Indian Journal of Public Health Research \& Development 2019, 10(8).

2. Petersen PE. World Health Organization global policy for improvement of oral health - World Health Assembly 2007. Int Dent J 2008;58:115-21.

3. World Health Organization. Strategies and Approaches in Oral Disease Prevention and Health Promotion. Geneva. Available from:

http://www.who.int/oral_health/strategies/ cont/en/print.html. [Last cited on 2010 Nov 06].

4. Krames patient's education book. Wisdom tooth removal your condition and treatment.

5. Ujwala Rohan Newadkar. Myths and misconceptions in general public toward ocular complications followed by the removal of upper teeth. 2017 Journal of Family Medicine and Primary Care | Published by Wolters Kluwer - Medknow.

6. Van der Bijl P, Meyer D. "Ocular complications of dental local anaesthesia," Journal of the South African Dental Association 1998;53(5):235-238.

7. Wei Cheong Ngeow. Transient Loss of Power of Accommodation in Eye Following Inferior Alveolar Nerve Block: Report of 2 Cases. December 2006/January 2007, 72(10).

8. Sarma CM, Babu BV, Manjulamma M. Sixth nerve palsy following dental anaesthesia. Indian $\mathrm{J}$ Ophthalmol 1989;37:27. 